\title{
Evidenciadores de biofilme em prótese total: avaliação clínica e antimicrobiana
}

\section{Biofilm disclosing agents in complete denture: clinical and antimicrobial evaluation}

\author{
Cláudia Helena Lovato da Silva* \\ Helena de Freitas Oliveira Paranhos** \\ Isabel Yoko Ito***
}

\begin{abstract}
RESUMO: Este trabalho avaliou a capacidade em corar, a facilidade de remoção e a ação antimicrobiana de evidenciadores de biofilme dental em prótese total. A capacidade em corar foi avaliada por método visual aplicando-se evidenciadores sobre a superficie interna da prótese total superior. Após fotografia, as próteses coradas foram escovadas (escova e dentifrício específicos para prótese total) e novamente fotografadas. Os diapositivos foram projetados em folhas de papel (aumento de $10 \mathrm{X}$ ); as áreas total e corada das próteses contornadas com grafite, recortadas e pesadas, para obtenção, em porcentagem, dos resultados da facilidade de remoção. A ação antimicrobiana foi avaliada pelo método de difusão em ágar e os resultados obtidos pela medida dos aros e halos de inibição formados. A melhor capacidade em corar foi apresentada pelo azul de metileno $(0,05 \%)$, eritrosina $(5 \%)$, fluoresceína sódica (1\%), Replak e vermelho neutro $(1 \%)$. Eosina $(1 \%)$, fluoresceína sódica $(1 \%)$ e eritrosina $(5 \%)$ apresentaram a maior facilidade de remoção. Não apresentaram ação antimicrobiana eosina (1\%), eritrosina (5\%), fluoresceína sódica (1\%), proflavina $(0,3 \%)$, Replak e vermelho neutro (1\%). As soluções que apresentaram maior capacidade de corar, facilidade de remoção e ausência de ação antimicrobiana, requisitos necessários para auxiliar estudos que avaliam métodos de higiene e de orientação aos pacientes, foram eosina (1\%), vermelho neutro $(1 \%)$ e eritrosina $(5 \%)$.
\end{abstract}

UNITERMOS: Prótese total; Biofilmes; Pigmentos; Resinas acrílicas.

\begin{abstract}
This study evaluated the disclosing ability, removal facility and antimicrobial effect of biofilm disclosing agents applied on complete dentures. Disclosing ability was evaluated by means of the visual method. The solutions were applied on the internal surface of dentures. After being photographed, the dentures were brushed with denture-specific brush and dentifrice and photographed again. The obtained slides were projected on paper (10 X amplification) and the total and stained surfaces were outlined with graphite, cut off and weighed, in order to assess removal facility. The evaluation of antimicrobial effects was carried out by means of the method of diffusion in agar, and the results were obtained by measuring the length of the halos and rings. In terms of disclosing ability, the best solutions were $0.05 \%$ methylene blue, $5 \%$ erythrosin, $1 \%$ sodic fluorescein, Replak and 1\% neutral red. One percent eosin, $1 \%$ sodic fluorescein and $5 \%$ erythrosin were the most easily removed solutions. One percent eosin, $5 \%$ erythrosin, $1 \%$ sodic fluorescein, $0.3 \%$ proflavine, Replak and $1 \%$ neutral red presented no antimicrobial effect. The solutions which presented the greatest disclosing ability and removal facility as well as absence of antimicrobial effect - which are essential requirements in the assessment of hygiene methods and guidance on oral health - were $1 \%$ eosin, $1 \%$ neutral red and $5 \%$ erythrosin.
\end{abstract}

UNITERMS: Denture, complete; Biofilms; Pigments; Acrylic resins.

\section{INTRODUÇÃO}

Os estudos que avaliam a saúde bucal de usuários de prótese totais concluem que a higiene desses aparelhos é precária. Entre as dificuldades para realização de uma boa limpeza, incluem a falta de orientação do paciente, as características das próteses, a diminuição da habilidade motora da maioria dos pacientes devido à idade e a falta de materiais específicos no mercado ${ }^{9,11,21}$.
Outro fator importante relacionado à higienização de próteses totais é o conhecimento dos materiais e métodos de quantificação do biofilme formado, procedimento importante para testar a eficácia dos produtos de higiene e para indicar ao profissional e paciente como e onde se deposita o biofilme sobre a prótese total ${ }^{3-6,15-19}$. A quantificação do biofilme em dentes naturais é estudada e apresentada na literatura ${ }^{2,7,11,13,20,23}$, mas em prótese total, é um

\footnotetext{
*Professora Assistente; **Professora Doutora - Departamento de Materiais Dentários e Prótese da Faculdade de Odontologia de Ribeirão Preto da Universidade de São Paulo.

***Professora Titular da Disciplina de Microbiologia do Departamento de Ciências da Saúde da Faculdade de Ciências Farmacêuticas de Ribeirão Preto da Universidade de São Paulo.
} 
Silva CHL da, Paranhos H de FO, Ito IY. Evidenciadores de biofilme em prótese total: avaliação clínica e antimicrobiana. Pesqui Odontol Bras 2002;16(3):270-275.

procedimento difícil devido à escassez de estudos e por não ser algo realizado rotineiramente na clínica odontológica. Em muitas investigações, soluções evidenciadoras têm sido utilizadas para quantificar o biofilme da prótese total.

O objetivo deste trabalho foi avaliar a eficiência de evidenciadores de biofilme dental sobre o biofilme da prótese total quanto a capacidade em corar, facilidade de remoção do evidenciador da resina acrílica e dos dentes artificiais e ação antimicrobiana (in vitro) contra microrganismos especificos.

\section{MATERIAIS E MÉTODOS}

\section{Capacidade em corar o biofilme}

As soluções utilizadas e suas concentrações estão apresentadas no Quadro 1.

\section{Seleção dos pacientes}

Foram selecionados da clínica de Prótese Total da Faculdade de Odontologia de Ribeirão Preto (Universidade de São Paulo) 28 pacientes, 5 homens e 23 mulheres, com idade entre 35 e 60 anos, estado de saúde geral bom (verificado pelo prontuário clínico de cada paciente), portadores de prótese total dupla confeccionadas em resina acrílica termoativada na cor rosa e com dentes de acrílico sem fraturas ou emendas e com período de uso entre 1 e 10 anos. O Índice Aditivo ${ }^{1}$ foi utilizado para selecionar próteses totais com uma quantidade mínima de biofilme.

\section{Aplicação da solução evidenciadora}

As próteses totais foram enxaguadas em água corrente por 5 segundos e secas por jato de ar por 10 segundos. Com um "swab", cada evidenciador foi aplicado sobre a superficie interna de 4 próteses totais superiores. Em seguida, foram novamente enxaguadas por 5 segundos para remoção

QUADRO 1 - Soluções evidenciadoras de biofilme e concentrações utilizadas.

\begin{tabular}{|r|l|l||}
\hline N $^{\mathrm{o}}$ & Soluções evidenciadoras & Concentração das soluções \\
\hline 1 & Azul de metileno & Alcoólica a $0,05 \%$ \\
\hline 2 & Eosina & Aquosa a $1,0 \%$ \\
\hline 3 & Eritrosina & Aquosa a $5,0 \%$ \\
\hline 4 & Fluoresceína sódica & Glicerinada a $1,0 \%$ \\
\hline 5 & Proflavina monossulfato & Aquosa a $0,3 \%$ \\
\hline 6 & Replak & Comercial \\
\hline 7 & Vermelho neutro & Aquosa a $1,0 \%$ \\
\hline
\end{tabular}

do excesso do evidenciador e secas por 10 segundos. A capacidade em corar foi avaliada visualmente e classificada da seguinte forma: 1) excelente - evidenciadores que coraram o biofilme de forma intensa, possibilitando a correta determinação do contorno das áreas contendo biofilme; 2) bom - evidenciadores que coraram o biofilme de forma mais fraca, mas possibilitaram a determinação do contorno das áreas com biofilme; 3) ruim - evidenciadores que não coraram o biofilme, impossibilitando a distinção entre a cor da base da prótese e a cor característica do evidenciador.

\section{Facilidade de remoção do evidenciador da resina acrílica e dos dentes artificiais}

A metodologia empregada foi similar àquela utilizada por Paranhos et $a .^{20}$ (2000). A superficie analisada foi fotografada com filme Ektacrome Asa 100, com tempo de exposição e técnica fotográfica padronizada em ângulo de $90^{\circ}$. Foram realizados 3 registros fotográficos da superficie interna de cada prótese: $1^{\circ}$ registro - fotografia da superficie corada; $2^{\circ}$ registro - fotografia da superficie após as dentaduras terem sido higienizadas com uma escova macia (Johnson \& Johnson Ltda., São Paulo, Brasil) e uma pasta para dentadura (Dentu Creme, Dentco, Inc. Jersey City, EUA) por 1 minuto; $3^{\circ}$ registro - fotografia da superfície após os evidenciadores terem sido reaplicados na superficie interna da prótese total superior. Este serviu como um controle, possibilitando a comparação da área corada antes da escovação com a área corada após a escovação, permitindo verificar a capacidade do evidenciador em corar somente o biofilme e/ou áreas da prótese sem biofilme. Os diapositivos obtidos foram projetados em aumento de $10 \mathrm{X}$ sobre folha de papel $\left(297\right.$ x $432 \mathrm{~mm}$ e $\left.75 \mathrm{~g} / \mathrm{m}^{2}\right)$ e o contorno da área total e corada da prótese foi realizado com grafite. Estas áreas foram recortadas do papel e pesadas em balança analítica (Metler Toledo, Suiça). A porcentagem de biofilme foi calculada como a relação entre o peso da área corada multiplicado por 100 e o peso da área total da prótese.

\section{Ação antimicrobiana dos evidenciadores}

O método utilizado foi o de difusão em ágar. Empregaram-se dois meios de cultura (Brain Heart Infusion - BHI e ágar Mueller-Hinton Medium - MH). Os microrganismos e suas origens estão apresentados no Quadro 2.

Os microrganismos Streptococcus mutans, Streptococcus sobrinus e Enterococcus faecalis foram semeados em BHI e Micrococcus luteus, 
Silva CHL da, Paranhos H de FO, Ito IY. Evidenciadores de biofilme em prótese total: avaliação clínica e antimicrobiana. Pesqui Odontol Bras 2002;16(3):270-275.

QUADRO 2 - Origem dos microrganismos utilizados como indicadores da ação antimicrobiana dos evidenciadores de biofilme.

\begin{tabular}{||c|l|l||}
\hline \hline$N^{\circ}$ & \multicolumn{1}{|c||}{ Microrganismo } & \multicolumn{1}{|c||}{ Origem } \\
\hline K1 & Streptococcus mutans & Dente natural \\
\hline K3 & Streptococcus sobrinus & Dente natural \\
\hline H1 & Streptococcus mutans & Dente natural \\
\hline S1 & Streptococcus mutans & Espanha \\
\hline Ef & Enterococcus faecalis & ATCC 10541 \\
\hline Ml & Micrococcus luteus & ATCC 9341 \\
\hline St & Staphylococcus aureus & ATCC 25923 \\
\hline 8+ & Staphylococcus aureus & Prótese total \\
\hline Epi & Staphylococcus epidermidis & Saliva de paciente \\
\hline Ec & Escherichia coli & ATCC 25922 \\
\hline $\mathrm{Pa}$ & Pseudomonas aeruginosa & ATCC 27853 \\
\hline $\mathrm{Ca}$ & Candida albicans & ATCC 1023 \\
\hline $\mathrm{Da}$ & Candida glabrata & Prótese total \\
\hline \hline
\end{tabular}

TABELA 1 - Capacidade das soluções evidenciadoras em corar o biofilme.

\begin{tabular}{l|c|c|c}
\hline \hline \multirow{2}{*}{ Solução evidenciadora } & \multicolumn{3}{c}{ Capacidade em corar } \\
\cline { 2 - 4 } & Excelente & Boa & Ruim \\
\hline Azul de metileno a $0,05 \%$ & $\mathrm{X}$ & - & - \\
\hline Eosina a 1\% & - & $\mathrm{X}$ & - \\
\hline Eritrosina a 5\% & $\mathrm{X}$ & - & - \\
\hline Fluoresceína sódica a 1\% & $\mathrm{X}$ & - & - \\
\hline Proflavina monossulfato a $0,3 \%$ & - & $\mathrm{X}$ & - \\
\hline Replak & $\mathrm{X}$ & - & - \\
\hline Vermelho neutro a $1 \%$ & $\mathrm{X}$ & - & - \\
\hline \hline
\end{tabular}

Staphylococcus aureus, Staphylococcus epidermidis, Escherichia coli, Pseudomonas aeruginosa, Candida albicans, Candida glabrata, em MH. As placas para o teste foram obtidas por adição dos microrganismos no meio de cultura a uma temperatura de $50^{\circ} \mathrm{C}$ com o auxílio de pipeta em uma concentração final de $10^{6} \mathrm{UFC} / \mathrm{ml}$ (cálculo realizado por meio de diluição e estimativa, baseado no MDI - "maximum dilution index"), com volume de $12 \mathrm{ml}$ nas placas de $20 \times 100 \mathrm{~mm}$, em câmera de fluxo vertical (Veco, Campinas, SP). Com uma pinça esterilizada, os discos de papel foram embebidos em $5 \mathrm{ml}$ das soluções evidenciadoras e distribuídos uniformemente sobre o meio de cultura. As
TABELA 2 - Resultados (\%) dos 3 registros realizados para cada prótese.

\begin{tabular}{|c|c|c|c|}
\hline \multirow{2}{*}{ Soluções } & \multicolumn{3}{|c|}{ Registros } \\
\hline & $1^{\circ}$ & $2^{\circ}$ & $3^{\circ}$ \\
\hline \multirow{4}{*}{$\begin{array}{c}\text { Azul de metileno } \\
\text { a } 0,05 \%\end{array}$} & 32,29 & 5,96 & 31,16 \\
\hline & 49,74 & 9,13 & 26,02 \\
\hline & 5,55 & 2,99 & 4,49 \\
\hline & 26,29 & 3,82 & 17,31 \\
\hline \multirow{4}{*}{ Eosina a $1 \%$} & 6,92 & 0 & 2,08 \\
\hline & 4,43 & 0 & 1,44 \\
\hline & 1,42 & 0 & 0,47 \\
\hline & 8,96 & 0 & 1,08 \\
\hline \multirow{4}{*}{ Eritrosina a 5\% } & 4,50 & 0,29 & 4,19 \\
\hline & 7,05 & 0 & 6,22 \\
\hline & 11,05 & 5,05 & 2,03 \\
\hline & 12,22 & 3,11 & 8,33 \\
\hline \multirow{4}{*}{$\begin{array}{l}\text { Fluoresceína } \\
\text { sódica a } 1 \%\end{array}$} & 13,09 & 0 & 0,68 \\
\hline & 13,08 & 3,20 & 9,32 \\
\hline & 16,57 & 0 & 11,11 \\
\hline & 25,13 & 1,05 & 11,45 \\
\hline \multirow{4}{*}{$\begin{array}{c}\text { Proflavina } \\
\text { monossulfato } \\
\text { a } 0,3 \%\end{array}$} & 7,88 & 0 & 5,47 \\
\hline & 18,36 & 5,67 & 16,5 \\
\hline & 32,06 & 4,18 & 31,69 \\
\hline & 13,65 & 1,09 & 5,83 \\
\hline \multirow{4}{*}{ Replak } & 23,47 & 8,07 & 18,22 \\
\hline & 3,13 & 0,44 & 0,91 \\
\hline & 32,90 & 1,32 & 14,93 \\
\hline & 22,58 & 0,82 & 4,11 \\
\hline \multirow{4}{*}{$\begin{array}{c}\text { Vermelho neutro } \\
\text { a } 1 \%\end{array}$} & 25,26 & 5,26 & 11,74 \\
\hline & 16,80 & 2,52 & 9,83 \\
\hline & 13,27 & 0,88 & 6,25 \\
\hline & 8,55 & 4,41 & 8,48 \\
\hline
\end{tabular}

placas foram incubadas em estufas a $37^{\circ} \mathrm{C}$ e, em seguida, os diâmetros dos halos e aros de inibição foram medidos em $\mathrm{mm}$.

\section{RESULTADOS}

Os resultados, obtidos por método visual, da classificação das soluções quanto à capacidade em corar o biofilme estão apresentados na Tabela 1 . 
Silva CHL da, Paranhos H de FO, Ito IY. Evidenciadores de biofilme em prótese total: avaliação clínica e antimicrobiana. Pesqui Odontol Bras 2002;16(3):270-275.

Os resultados (\%) da área corada sobre a área total dos três registros, para posterior avaliação da facilidade de remoção, estão apresentados na Tabela 2 .

Sobre os resultados da Tabela 2, aplicou-se análise de variância, que mostrou haver diferença significativa entre as soluções ao nível de $1 \%$. Por haver mais de duas médias envolvidas, efetuou-se o teste de Tukey (Tabela 3) e os resultados estão apresentados na Tabela 3.

As letras apresentadas à frente de cada média têm a função de indicar se elas são estatisticamente iguais. Como houve sobreposição de médias (exemplo: $0,38=0,37$ e $0,27=0,23$ e $0,23=0,06$ ) aplicou-se o teste de Scheffé, que indicou haver diferença significante entre a solução de eosina a 1\%

TABELA 3 - Verificação da facilidade de remoção das soluções (teste de Tukey).

\begin{tabular}{|c|c|c|}
\hline Soluções & Médias & $\begin{array}{l}\text { Valor do teste } \\
\mathrm{p}(\mathrm{H} 0)=1 \%\end{array}$ \\
\hline Azul de metileno a $0,05 \%$ & $0,49 \mathrm{a}$ & \multirow{7}{*}{0,20} \\
\hline Proflavina monossulfato a $0,3 \%$ & $0,38 \mathrm{ab}$ & \\
\hline Vermelho neutro a $1 \%$ & $0,38 \mathrm{ab}$ & \\
\hline Replak & $0,37 \mathrm{ab}$ & \\
\hline Fuoresceína sódica a $1 \%$ & $0,27 \mathrm{bc}$ & \\
\hline Eritrosina a $5 \%$ & $0,23 \mathrm{bcd}$ & \\
\hline Eosina a $1 \%$ & $0,06 \mathrm{~cd}$ & \\
\hline
\end{tabular}

Letras diferentes indicam diferença estatística significante. e as demais soluções, entre as quais não houve diferença significante.

$\mathrm{Na}$ Tabela 4, estão apresentadas as médias (\%) da interação registros versus soluções (obtidas por meio da análise de variância). Estas médias permitem verificar, numericamente, qual solução apresentou a maior capacidade em corar o biofilme $\left(1^{\circ}\right.$ registro), maior facilidade de remoção ( $2^{\circ}$ registro) e maior capacidade em corar a prótese sem biofilme $\left(3^{\circ}\right.$ registro $)$.

O azul de metileno foi a solução que corou melhor o biofilme $(0,84 \%)$, a mais dificil de ser removida $(0,50 \%)$ e a que mais corou a superficie da prótese sem o biofilme presente $(0,74 \%)$.

Nas Tabelas 5 e 6, estão apresentadas as medidas dos halos e aros de inibição do crescimento de

TABELA 4 - Médias (\%) da interação soluções versus registros.

\begin{tabular}{l|c|c|c}
\hline \multirow{2}{*}{\multicolumn{1}{c|}{ Soluções }} & \multicolumn{3}{c}{ Registros } \\
\cline { 2 - 4 } & $1^{\text {o }}$ & $2^{\text {o }}$ & $3^{\text {o }}$ \\
\hline Azul de metileno a 0,05\% & 0,84 & 0,50 & 0,74 \\
\hline Eosina a 1\% & 0,49 & 0 & 0,30 \\
\hline Eritrosina a 5\% & 0,58 & 0,22 & 0,48 \\
\hline Fluoresceína sódica a 1\% & 0,70 & 0,21 & 0,51 \\
\hline Proflavina monossulfato a 0,3\% & 0,75 & 0,31 & 0,69 \\
\hline Replak & 0,77 & 0,34 & 0,62 \\
\hline Vermelho neutro a 1\% & 0,73 & 0,42 & 0,61 \\
\hline \hline
\end{tabular}

TABELA 5 - Medida ( $\mathrm{mm}$ ) dos halos e aros de inibição do crescimento dos microrganismos causada pelas soluções evidenciadoras em meio BHI.

\begin{tabular}{|c|c|c|c|c|c|c|c|c|c|c|c|c|c|c|}
\hline \multirow{3}{*}{$\begin{array}{l}\text { Microrganismos } \\
\text { e origem }\end{array}$} & \multicolumn{14}{|c|}{ Soluções } \\
\hline & \multicolumn{2}{|c|}{$\begin{array}{l}\text { Azul de meti- } \\
\text { leno }(0,05 \%)\end{array}$} & \multicolumn{2}{|c|}{ Eosina $(1 \%)$} & \multicolumn{2}{|c|}{$\begin{array}{c}\text { Eritrosina } \\
(5 \%)\end{array}$} & \multicolumn{2}{|c|}{$\begin{array}{l}\text { Fluoresceína } \\
\text { sódica }(1 \%)\end{array}$} & \multicolumn{2}{|c|}{$\begin{array}{c}\text { Proflavina } \\
(0,3 \%)\end{array}$} & \multicolumn{2}{|c|}{ Replak } & \multicolumn{2}{|c|}{$\begin{array}{l}\text { Vermelho } \\
\text { neutro (1\%) }\end{array}$} \\
\hline & Halo & Aro & Halo & Aro & Halo & Aro & Halo & Aro & Halo & Aro & Halo & Aro & Halo & Aro \\
\hline $\begin{array}{l}\text { Streptococcus mutans } \\
\text { (dente natural) }\end{array}$ & 22 & 6 & 0 & 0 & 15 & 4 & 0 & 0 & 19 & 7 & 15 & 4 & 0 & 0 \\
\hline $\begin{array}{l}\text { Streptococcus sobrinus } \\
\text { (dente natural) }\end{array}$ & 18 & 5 & 0 & 0 & 16 & 4 & 0 & 0 & 18 & 5 & 14 & 3 & 0 & 0 \\
\hline $\begin{array}{l}\text { Streptococcus mutans } \\
\text { (dente natural) }\end{array}$ & 10 & 1 & 10 & 1 & 16 & 4 & 0 & 0 & 15 & 4 & 14 & 3 & 0 & 0 \\
\hline $\begin{array}{l}\text { Streptococcus mutans } \\
\text { (Espanha) }\end{array}$ & 10 & 1 & 11 & 2 & 16 & 4 & 0 & 0 & 14 & 3 & 14 & 4 & 0 & 0 \\
\hline $\begin{array}{l}\text { Enterococcus faecalis } \\
\text { (ATCC 10541) }\end{array}$ & 16 & 4 & 11 & 2 & 14 & 3 & 9 & 1 & 8 & 1 & 31 & 4 & 0 & 0 \\
\hline
\end{tabular}


Silva CHL da, Paranhos H de FO, Ito IY. Evidenciadores de biofilme em prótese total: avaliação clínica e antimicrobiana. Pesqui Odontol Bras 2002;16(3):270-275.

TABELA 6 - Medida (mm) dos halos e aros de inibição do crescimento dos microrganismos causada pelas soluções evidenciadoras em meio $\mathrm{MH}$.

\begin{tabular}{|c|c|c|c|c|c|c|c|c|c|c|c|c|c|c|}
\hline \multirow{3}{*}{$\begin{array}{l}\text { Microrganismos } \\
\text { e origem }\end{array}$} & \multicolumn{14}{|c|}{ Soluções } \\
\hline & \multicolumn{2}{|c|}{$\begin{array}{l}\text { Azul de meti- } \\
\text { leno }(0,05 \%)\end{array}$} & \multicolumn{2}{|c|}{ Eosina $(1 \%)$} & \multicolumn{2}{|c|}{$\begin{array}{l}\text { Eritrosina } \\
\quad(5 \%)\end{array}$} & \multicolumn{2}{|c|}{$\begin{array}{l}\text { Fluoresceína } \\
\text { sódica }(1 \%)\end{array}$} & \multicolumn{2}{|c|}{$\begin{array}{l}\text { Proflavina } \\
(0,3 \%)\end{array}$} & \multicolumn{2}{|c|}{ Replak } & \multicolumn{2}{|c|}{$\begin{array}{r}\text { Vermelho } \\
\text { neutro }(1 \%\end{array}$} \\
\hline & Halo & Aro & Halo & Aro & Halo & Aro & Halo & Aro & Halo & Aro & Halo & Aro & Halo & Aro \\
\hline $\begin{array}{l}\text { Micrococcus luteus } \\
\text { (ATCC 9341) }\end{array}$ & 12 & 2 & 9 & 1 & 12 & 2 & 17 & 5 & 0 & 0 & 15 & 4 & 10 & 1 \\
\hline $\begin{array}{l}\text { Staphylococcus aureus } \\
\text { (ATCC 25923) }\end{array}$ & 13 & 2 & 10 & 1 & 14 & 4 & 13 & 3 & 9 & 1 & 12 & 3 & 10 & 1 \\
\hline $\begin{array}{l}\text { Staphylococcus aureus } \\
\text { (prótese total) }\end{array}$ & 11 & 2 & 14 & 3 & 14 & 10 & 13 & 3 & 9 & 1 & 13 & 3 & 11 & 1 \\
\hline $\begin{array}{l}\text { Staphylococcus } \\
\text { epidermidis } \\
\text { (saliva de paciente) }\end{array}$ & 13 & 3 & 13 & 3 & 14 & 4 & 14 & 3 & 8 & 1 & 18 & 5 & 11 & 2 \\
\hline $\begin{array}{l}\text { Escherichia coli } \\
\text { (ATCC 25922) }\end{array}$ & 10 & 1 & 0 & 0 & 0 & 0 & 0 & 0 & 0 & 0 & 9 & 1 & 0 & 0 \\
\hline $\begin{array}{l}\text { Pseudomonas aeruginosa } \\
\text { (ATCC 27853) }\end{array}$ & 0 & 0 & 0 & 0 & 0 & 0 & 0 & 0 & 0 & 0 & 0 & 0 & 0 & 0 \\
\hline $\begin{array}{l}\text { Candida albicans } \\
\text { (ATCC 1023) }\end{array}$ & 12 & 2 & 0 & 0 & 0 & 0 & 0 & 0 & 0 & 0 & 0 & 0 & 0 & 0 \\
\hline $\begin{array}{l}\text { Candida glabrata } \\
\text { (prótese total) }\end{array}$ & 13 & 4 & 0 & 0 & 0 & 0 & 0 & 0 & 0 & 0 & 31 & 14 & 28 & 11 \\
\hline
\end{tabular}

microrganismos causadas pelas soluções evidenciadoras.

\section{DISCUSSÃO}

Este trabalho teve como objetivo identificar soluções evidenciadoras capazes de corar o biofilme da prótese total, que fossem fáceis de serem removidas da base de resina e dos dentes artificiais e que não apresentassem ação antimicrobiana. As próteses superiores dos pacientes foram selecionadas de acordo com o Índice Aditivo ${ }^{1}$ para padronização da quantidade de biofilme presente na superficie interna das próteses totais, permitindo assim, afirmar que as soluções com pouca capacidade em corar ou que não coraram o biofilme não tiveram este comportamento pela ausência de biofilme na superficie das próteses.

A metodologia utilizada para realização do trabalho fundamentou-se na literatura existente ${ }^{1,5,21}$, a qual mede a quantidade de biofilme através de diapositivos coloridos projetados em folha de papel, onde se atribuem escores para quantificar o biofilme. Neste trabalho, utilizou-se o método de pesagem de papel para obtenção de dados numéricos por serem mais objetivos que a atribuição de escores. As soluções foram testadas clinicamente e avaliadas visualmente (Tabela 1), sendo que 5 foram excelentes e 2 boas, quanto à capacidade em corar o biofilme da prótese total, permitindo a identificação das áreas contendo biofilme. Esse fator é importante quando da orientação ao paciente a respeito da localização do biofilme por facilitar sua remoção por escovação e manutenção das próteses totais.

Após a aplicação de análise estatística (Tabela 3), as soluções que apresentaram melhores resultados para facilidade de remoção foram eosina a 1\%, eritrosina a 5\%, fluoresceína sódica a 1\%, Replak, vermelho neutro a $1 \%$, proflavina a $0,3 \%$ e azul de metileno a $0,05 \%$, respectivamente (Tabela 4).

Os trabalhos encontrados na literatura que mencionaram o uso de evidenciadores para avaliação e quantificação do biofilme não se referiram à ação antimicrobiana das soluções utilizadas ${ }^{1,2,3,8,10}$, exceto Begue et al. ${ }^{2}$ (1966) que estudou a eritrosina. Estas informações são importantes nos estudos que avaliam a atividade antimicrobiana de higienizadores de próteses totais. O uso aleatório de um evidenciador pode interferir nos resultados se 
Silva CHL da, Paranhos H de FO, Ito IY. Evidenciadores de biofilme em prótese total: avaliação clínica e antimicrobiana. Pesqui Odontol Bras 2002;16(3):270-275.

ele apresentar capacidade bactericida e/ou bacteriana.

$\mathrm{Na}$ avaliação da ação antimicrobiana, as soluções que não apresentaram ação contra leveduras (Candida albicans) e Streptococcus do grupo mutans foram eosina a 1\%, fluoresceína sódica a $1 \%$ e vermelho neutro a $1 \%$. As soluções que não apresentaram ação somente contra leveduras foram eritrosina a 5\%, proflavina a 0,3\% e Replak. A atenção para esse grupo de soluções foi destacada porque o biofilme é formado principalmente por Streptococcus do grupo mutans e

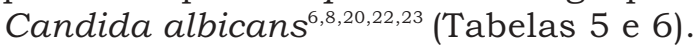

\section{REFERÊNCIAS}

1. AmbjØrnsen E, Rise J, Haugejorden O. A study of examiner errors associated with measurement of denture plaque. Acta Odontol Scand 1984;42(3):183-91.

2. Begue WJ, Bard RC, Koegne GW. Microbial inhibition by erythrosin. J Res 1966;45:1464-7.

3. Block PL, Lobene RR, Derdivanis J. P. A two-tone dye test for dental plaque. J Periodontol 1972;43(7):423-6.

4. Budtz-JØrgensen E. A 3-month study of enzymes as denture cleansers. J Oral Rehabil 1978;5(1):35-9.

5. Budtz-JØrgensen E, Knudsen AM. Chlorhexidine gel and Steradent ${ }^{\mathbb{B}}$ employed in cleaning dentures. Acta Odontol Scand 1978;36(2):83-7.

6. Budtz-JØrgensen E, Theilade E, Theilade J. Quantitative relationship between yeast and bacteria in denture induced stomatitis. Scand J Dent Res 1983;91(2):134-42.

7. Caride ER, Rossi GH, Rezzano SM. Substâncias revelantes. Odontol Panam 1974;2:43-50.

8. Connor JN, Schoenfeld CM, Taylor RL. Study of in vivo plaque formation. J Dent Res 1976;55(3):481-8.

9. Cumming CG, Wight C, Blackwell CL, Wray D. Denture stomatitis in the elderly. Oral Microbiol Immunol 1990;5(8):82-5.

10. Hefferren JJ. Use of ultraviolet illumination in oral diagnoses. J Am Dent Assoc 1971;82(6):1252-60.

11. Hoad-Reddick G, Grant AA, Griffits CS. Investigation into the cleanness of dentures in an elderly population. $\mathrm{J}$ Prosthet Dent 1990;64(1):48-52.

12. Hutchins PW, Parker WA. A clinical evaluation of the ability of denture cleaning solutions to remove dental plaque from prosthetic devices. N Y State Dent J 1973;39:363-7.

13. Jeganathan S, Thean HPY, Thong KT, Chan YC, Singh M. A clinically viable index for quantifying denture plaque. Quintessence Int 1996;27(8):569-73.

\section{CONCLUSÕES}

As soluções que apresentaram capacidade em corar o biofilme, facilidade de remoção da superficie da prótese e não apresentaram ação antimicrobiana foram eosina a $1 \%$, vermelho neutro a $1 \%$ e fluoresceína sódica a 1\%. Essas soluções podem ser empregadas em estudos que avaliam produtos específicos de higiene e o biofilme da prótese total qualitativa e quantitativamente e podem também serem instituídas como auxiliares nos métodos de remoção do biofilme pelos usuários de próteses totais.

14. Keng SB, Lim M. Denture plaque distribution and effectiveness of a perborate-containing denture cleanser. Quintessence Int 1996;27(5):341-5.

15. Kulak Y, Arikan A, Albak S, Okar Y, Kazazoglu E. Scanning electron microscopic examination of different cleansers: surface contaminant removal from dentures. J Oral Rehabil 1997;24(6):209-215.

16. Lang NP, Ostergaard E, Löe H. A fluorescent plaque disclosing agent. J Periodontol Res 1972;7:59-67.

17. Lecknes KN, Lie T. Erythrosin staining in clinical disclosure of plaque. Quintessence Int 1988;19(3):199-204.

18. Miese JB, Wade AB. Use of food colorants of plaque disclosing agents. J Clin Periodontol 1973;3:200-7.

19. Palenik CJ, Miller C. H. In vitro testing of three denture cleaning systems. J Prosthet Dent 1984;51(6):751-4.

20. Paranhos HFO, Panzeri H, Lara EHG, Candido RC, Ito IY. Capacity of denture plaque/biofilm removal and antimicrobial action of a new denture paste. Braz Dent $\mathrm{J}$ 2000;11(2):97-104.

21. Pietrokovski J, Azuelos J, Tau S, Mostavoy R. Oral findings in elderly nursing home residents in selected countries: oral hygiene conditions and plaque accumulation on denture surfaces. J Prosthet Dent 995;73(2):136-41.

22. Theilade E, Budtz-JØrgensen E. Predominant cultivable microflora of plaque on removable dentures in patients with denture induced stomatitis. Oral Microbiol Immunol 1988;3(1):8-13.

23. Walter B, Frank RM, Steuer P. Ultrastructural development of dated plaque in case of denture stomatitis. J Biol Buccale 1986;14(2):115-24.
Recebido para publicação em 08/08/01

Enviado para reformulação em 14/05/02

Aceito para publicação em 19/06/02 